\title{
Molluscicidal Effects of Aqueous Extracts of Selected Medicinal Plants from Makueni County, Kenya
}

\section{Kimeu B Mwonga ${ }^{1^{\star}}$, Njagi ENM waniki ${ }^{2}$, Yole S Dorcas ${ }^{1}$ and Ngugi M Piero ${ }^{2}$}

${ }^{1}$ Department of Biochemistry and Biotechnology, School of Biological and Life Sciences, Technical University of Kenya, P.O Box 52428-00200, Nairobi, Kenya ${ }^{2}$ Department of Biochemistry and Biotechnology, School of Pure and Applied Sciences, Kenyatta University, P.O Box 438844-00100, Nairobi, Kenya

\begin{abstract}
Schistosomiasis (also known as Bilharzia) is a disease caused by species of parasitic worms or helminths of the genus Schistosoma. It continues to be a serious worldwide public health problem. The pathological changes in schistosome infestations are caused mainly by the deposition of the eggs into various tissues and organs where granulomas or pseudo tubercles are formed around them. Schistosomes and their intermediate snail hosts are integral parts of the freshwater aquatic environments in which they are found. Biomphalaria and Bulinus are the two primary genera of snails capable of harbouring infections with Schistosoma mansoni and S. haematobium. Some of the methods of controlling of schistosomiasis include: control of snails, public health education, sanitation, and community-based chemotherapy employing praziquantel. No single method, regardless of location, has been shown to work because of the large number of environmental variables involved in the parasitic transmission. Some of the control programmes have been those that include some method of curbing transmission, including mollusciciding. The objective of this study was to bioscreen aqueous extracts of five medicinal plants identified using ethnobotanical information gathered from traditional healers for molluscicidal activity. Molluscicidal activity was assessed by determining the ability of various concentrations of the aqueous plant extracts to kill adult Biomphalaria pfeifferi, the intermediate host of Schistosoma mansoni. Of the five plant extracts, only the aqueous extracts of Aloe secundiflora, Aspilia pluriseta, Balanites aegyptiaca, Azadirachta indica and Amaranthus hybridus showed molluscicidal activity. This study has established that five plants, that is, Aloe secundiflora, Aspilia pluriseta, Balanites aegyptiaca, Azadirachta indica and Amaranthus hybridus have molluscicidal activity and recommends that toxicity studies be conducted to establish their safety in bilharzia control.
\end{abstract}

Keywords: Schistosomiasis; Biomphalaria pfeifferi; Molluscicidal activity; Schistosoma mansoni

\section{Introduction}

Schistosomiasis (also known as Bilharzia) is a debilitating disease caused by species of parasitic worms or helminths of the genus Schistosoma, which are also known as blood flukes. It is the second most prevalent tropical disease in Africa after malaria. Bilharzia is of great public health and social economic importance in the developing world. World Health Organization (WHO) reports estimate that 500-600 million people in 74 tropical and sub-tropical countries are at risk of schistosomiasis. Over 200 million people in these countries are infected, $85 \%$ of whom live in sub-Saharan Africa where $S$. haematobium, S. intercalatum and S. mansoni are endemic [1].

In Kenya, the two species of bilharziasis are Schistosoma mansoni and S. haematobium whose intermediate hosts are fresh water snails, Biomphalaria pffeiferi and Bulinus trancatus respectively [2].

At least four approaches to controlling infection have been tried at the community level. These are control of snails, public health education, sanitation, and community-based chemotherapy employing Niclosamide [3]. Selective molluscicide treatment in snail-infested bodies of water at main human contact points is the preferred way to approach controlling snail populations [3].

At least four approaches to controlling infection have been tried at the community level. These are control of snails, public health education, sanitation, and community-based chemotherapy employing praziquantel [3]. Selective molluscicidal treatment in snail-infested bodies of water at main human contact points is the preferred way to approach controlling snail populations ${ }^{3}$. Three drugs have been used for schistosomiasis treatment. These are Praziquantel (effective in the treatment of all forms of schistosomiasis, with hardly any side effects), Oxamniquine (used to treat intestinal schistosomiasis), and
Metrifonate (effective for the treatment of urinary schistosomiasis [4]. Praziquantel has been found to be more effective in treating $S$. haematobium infections compared to metrifonate and more effective in treating $S$. mansoni when compared with oxamniquine because it is effective when treating advanced hepatosplenic schistosomiasis, with few side effects. Praziquantel is currently the drug of choice for treatment of any kind of schistosomiasis. The main limitation is the cost which restricts its use in many developing countries. Unfortunately, the long-term worldwide application of Praziquantel coupled with the recent discovery of Praziquantel-tolerant schistosomes has generated concern over the development of drugs-resistant Schistosoma strains $[5,6]$. A large number of plant products, which possess molluscicidal activity, have been identified and used for treatment of schistosomes [7-12].

Traditional medicine, being a significant element in the cultural patrimony, still remains the main resource for a large majority of people in Kenya, for treating various diseases and ailments. It is against this background that this study was designed to evaluate the molluscicidal activities of crude aqueous extracts of Aloe secundiflora,

*Corresponding author: Kimeu Benjamin Mwonga, Department of Biochemistry and Biotechnology, School of Biological and Life Sciences, Technical University of Kenya, P.O Box 52428-00200, Nairobi, Kenya, Tel: +254 722245 459; E-mail: benkimeu72@gmail.com

Received October 21, 2015; Accepted November 11, 2015; Published November 13, 2015

Citation: Mwonga KB, Waniki NENM, Dorcas YS, Piero NM (2015) Molluscicidal Effects of Aqueous Extracts of Selected Medicinal Plants from Makueni County, Kenya. Pharm Anal Acta 6: 445. doi:10.4172/21532435.1000445

Copyright: (c) 2015 Mwonga KB, et al. This is an open-access article distributed under the terms of the Creative Commons Attribution License, which permits unrestricted use, distribution, and reproduction in any medium, provided the original author and source are credited. 
Balanites aegyptiaca, Aspilia pluriseta, Amaranthus hybridus, Psidium guajava and Azadirachta indica on Biomphalaria pfeifferi.

\section{Materials and Method}

\section{Collection and preparation of medicinal plant material}

The plant materials used in this study were collected from their natural habitats on the basis of ethnobotanical information. They were collected with bio-conservation aspects in mind from Kisau location, Makueni County. An acknowledged authority in taxonomy from the National Museums of Kenya (NMK) authenticated the botanical identity of the plants and a voucher specimen was deposited at the National Museums of Kenya Herbarium, Nairobi. A traditional medical practitioner provided the information on which plant to collect, what part to collect, the precise locality where it grows, when curative potency is maximal and the mode of preparation.

The plant parts collected were: leaves of Aloe secundiflora, roots of Balanites aegyptiaca, leaves of Aspilia pluriseta and Amaranthus hybridus, and roots and leaves of Psidium guajava and Azadirachta indica. The stems and roots were harvested and their barks peeled off while still fresh and cut into small pieces and then dried at room temperature for different periods of time depending on the succulence of the plant materials. Leaves were collected while green and dried in the same way. The root barks, stem barks and the leaves were separately ground into powder using an electric mill at The Technical University of Kenya. The powdered plant materials were kept at room temperature away from direct sunlight in closed dry plastic bags ready for extraction and use in bioassay.

\section{Extraction procedure}

Aqueous plant extraction was carried according to the method described by [13]. $100 \mathrm{~g}$ the powdered plant material were boiled in one litre of distilled water for $2 \mathrm{~h}$. After boiling, the solution was allowed to cool at room temperature. The extract was then decanted into a 1 litre clean dry conical flask and filtered through a No. 1 Whatman filter paper under vacuum pump into a $500 \mathrm{~mL}$ clean dry conical flask. Decantation and filtration processes were repeated until the sample became clear. The filtrate was freeze-dried, weighed and stored in an airtight container at room temperature until it was used for bioassay.

\section{Preparation of extracts for molluscicidal bioassay}

The plant extracts for testing molluscicidal activity were prepared following the procedure described by [14]. A stock solution of $80 \mathrm{ppm}$ was prepared for each of the plant preparations. This was achieved by weighing separately, $80 \mathrm{mg}$ of the freeze-dried plant materials, which was placed in $1000 \mathrm{~mL}$ of chlorine free water and boiled for 5 minutes. This gave $80 \mathrm{mg} / \mathrm{L}$ that is $80 \mathrm{ppm}$. Half of the prepared plant extract $(0.5$ L) was frozen and stored at $-20^{\circ} \mathrm{C}$ and the remaining stock was diluted to obtain concentrations of 40 and $10 \mathrm{mg} / \mathrm{L}$ for each preparation

\section{Laboratory animals}

Biomphalaria pfeifferi snails were collected from Mwea Irrigation Scheme in Mbeere South subcounty, Embu county of Kenya. They were screened for schistosomes under strong light (100 watts) for $2 \mathrm{~h}$ for six consecutive weeks to exclude infections from the wild. Negative snails were housed in temperature controlled $\left(25-27^{\circ} \mathrm{C}\right)$ and light-controlled (12 h light/12 h dark) snail room at the Institute of Primate Research (IPR), Nairobi, Kenya. They were placed in water tanks containing nonchlorinated tap water and the water was changed twice a week. Soft lettuce (dipped in hot water and cooled) was added to feed the snails.

\section{Evaluation of molluscicidal activity}

This was undertaken following the method of $[15,16]$. Biomphalaria pfeifferi snails were divided into five groups of fifty snails each. Group I (negative control) was exposed to $200 \mathrm{ml}$ of chlorine-free water for $24 \mathrm{~h}$. Group II (positive control) was exposed to $4 \mathrm{mg}$ of Niclosamide (reference molluscicide) in a volume of $200 \mathrm{ml}$ of chlorine-free water for $24 \mathrm{~h}$. Groups III, IV and V were exposed to the crude aqueous extracts of the six medicinal plants each at concentrations of 80,40 and $10 \mathrm{ppm}$ respectively in a total volume of $200 \mathrm{~mL}$ chlorine-free water for 24 hours. After $24 \mathrm{~h}$ of exposure, the snails were washed, placed in fresh non - chlorinated water, provided with lettuce to feed on, and allowed a recovery period of 24 hours after which mortality was accessed by probing the snails with a wooden spatula to elicit typical withdrawal movements. Death was ascertained by observing the snails under a dissecting microscope for any heart activity. The number of dead snails was recorded.

\section{Data analysis}

The experimental data was analyzed using unpaired Student $\mathrm{t}$-test. This test determined whether there were any significant differences between the data obtained from animal groups treated with crude aqueous plant extracts and controls animal groups. A value $\mathrm{p}<0.05$ was considered significant. Instat statistical computer package was used.

\section{Results}

\section{Molluscicidal effect of the crude aqueous plant extracts}

The efficacy of the six plant extracts against B. pffeiferi was evaluated by counting the number of dead snails in the treated and untreated water. The Niclosamide treated (positive control) group had the highest number of deaths $(48.67 \pm 0.7)$ while dechlorinated water had the lowest $(2.3 \pm 1.9)$. All crude aqueous extracts had significantly higher snail deaths than dechlorinated water at all concentrations $(\mathrm{P}<0.05$; Table 1). At $80 \mathrm{ppm}$, A. hybridus caused a similar degree of snail mortality to Niclosamide ( $\mathrm{P}>0.05$; Table 1$)$. The other aqueous extracts had snail mortality significantly lower than Niclosamide $(\mathrm{P}<0.05)$ but higher than dechlorinated water (Table 1$)$. Mortality increased with increasing concentration of the extract for all the plant extracts. Snails exposed to A. hybridus and Niclosamide were weak and could not retract into their shells. Excess mucus secretion was

\begin{tabular}{|c|c|c|c|c|c|}
\hline \multirow[b]{2}{*}{ Plant extracts } & \multicolumn{5}{|c|}{ Treatment groups and dosage $(\mathrm{N}=50)$} \\
\hline & $\begin{array}{c}10 \\
\mathrm{ppm}\end{array}$ & $40 \mathrm{ppm}$ & $\begin{array}{c}80 \\
\mathrm{ppm}\end{array}$ & $\begin{array}{l}\text { Niclosamide } \\
(4 \mathrm{mg} / 200 \mathrm{ml})\end{array}$ & $\begin{array}{l}\text { Chlorine } \\
\text { free water }\end{array}$ \\
\hline Aloe secundiflora & $\begin{array}{l}9.0 \pm \\
2.6^{* a}\end{array}$ & $\begin{array}{l}11.6 \pm \\
2.3^{* a}\end{array}$ & $\begin{array}{c}20.0 \pm \\
2.3^{*}\end{array}$ & $48.67 \pm 0.7$ & $2.3 \pm 1.9$ \\
\hline Aspilia pluriseta & $\begin{array}{l}7.6 \pm \\
1.4^{* a}\end{array}$ & $\begin{array}{c}12.6 \pm \\
2.7^{*}\end{array}$ & $\begin{array}{c}24.7 \pm \\
1.2^{ \pm}\end{array}$ & - & - \\
\hline Psidium guajava & $\begin{array}{l}8.7 \pm \\
2.7^{* a}\end{array}$ & $\begin{array}{l}9.3 \pm \\
1.8^{* a}\end{array}$ & $\begin{array}{l}9.6 \pm \\
2.6^{* a}\end{array}$ & - & - \\
\hline Balanites aegyptiaca & $\begin{array}{l}11.3 \pm \\
3.0^{*}\end{array}$ & $\begin{array}{l}14.0 \pm \\
3.5^{\star} \mathrm{a}\end{array}$ & $\begin{array}{l}17.6 \pm \\
2.6^{*}\end{array}$ & - & - \\
\hline Azadirachta indica & $\begin{array}{c}13.3 \pm \\
4.4^{* a}\end{array}$ & $\begin{array}{l}19.0 \pm \\
2.6^{* a}\end{array}$ & $\begin{array}{c}28.7 \pm \\
3.2^{ \pm}\end{array}$ & - & - \\
\hline Amaranthus hybridus & $\begin{array}{c}15.3 \pm \\
0.7^{*}\end{array}$ & $\begin{array}{l}38.3 \pm \\
3.2^{* a}\end{array}$ & $\begin{array}{c}44.0 \pm \\
2.3^{\mathrm{a}}\end{array}$ & - & - \\
\hline
\end{tabular}

All values are expressed as Mean \pm SEM. ${ }^{*} \mathrm{P}<0.05$ for extract treated group versus Niclosamide-treated group by unpaired Student's t-test; ${ }^{a} P<0.05$ for extract-treated group versus chlorine-free water treated group by unpaired Student's t-test.

Table 1: Molluscicidal effects of crude aqueous extracts of Aloe secundiflora, Aspilia pluriseta, Psidium guajava, Balanites aegyptiaca, Azadirachta indica and Amaranthus hybridus on Biomphalaria pfeifferi snails. 
observed and the snails hardly fed. They attempted to crawl out of the test solution.

\section{Discussion}

The search for bioactive plants components which can be used as non-conventional molluscicides and anti-helminthes has received considerable attention in recent times because of the increasing, worldwide development of resistance to chemical molluscicides in molluscs populations respectively. However, scientific evidence to validate the use of plants remains limited [17].

As intermediate hosts, molluscs play a major role in the transmission of schistosomes; they are the sites of an intense multiplication of parasites. Thus, snail control strategies are considered a priority for the reduction of schistosomiasis transmission. A standardized procedure devised for the laboratory screening of synthetic chemical molluscicides [15] is used to evaluate plant molluscicides. It recommends that candidate compounds pass through three stages, preliminary screening, definitive screening and comprehensive evaluation. For preliminary screening, five snails are exposed to concentrations of 80,40 and 10 $\mathrm{mg} / \mathrm{l}$ of each crude plant extracts $[14,15]$. In the preliminary screening the aim is to separate materials into those without any molluscicidal activity and those with some, however weak [16].

In this study, preliminary screening of A. secundiflora, A. pluriseta, P. guajava, B. aegyptiaca, A. indica and A. hybridus for molluscicidal potency was carried out. The aqueous extracts of $A$. secundiflora, A. pluriseta, $P$. guajava, B. aegyptiaca and $A$. indica exhibited snail mortality above the naive control. However, this is considered statistically significant compared to the standard molluscicides. The highest molluscicidal effect was exhibited by $A$. hybridus and this is considered statistically insignificant compared to the standard molluscicide The mortality increased with increasing concentration of the plant extracts

Plant materials may release active ingredients slowly so that the effect on snail population is delayed, that is, the plant may act as a slow release matrix. In this mode, there may also be effects on feeding and oviposition. Other plant substances affect orientation and feeding behaviour [18]. A bioassay of whole plants or parts in which snails are killed within 24 hours at a dosage below $100 \mathrm{mg} / \mathrm{L}$ indicates that the molluscicide is released quickly and the material may be a good candidate for $\mathrm{LC}_{50}$ determination [16]. This is in agreement with findings of this study in which death of snails was observed within 24 hours exposure to concentrations below $100 \mathrm{mg} / \mathrm{L}$ of $A$. hybridus.

Snails exposed to A. hybridus exhibited behaviours that suggested they had been adversely affected by these plants. The snails were weak and could neither eat nor retract into their shells. They exhibited excessive mucus secretion and cessation of feeding. The snails were apparently irritated as observed by their desire to crawl out of the test solution in order to avoid contact with the treated water. Increased mucus production followed by increased mucus secretion as observed in this study is one of the first reactions of gastropods to many stressors, including mechanical stimuli or chemical irritation caused by molluscicidal chemical [18-20]. One effect of the extruded mucus is to form a protective barrier preventing direct contact between the toxin and the epithelia of the skin or digestive tract, so reducing the toxicity of the chemicals $[20,21]$.

The responses of $B$. pfeifferi upon exposure to the crude aqueous extract $A$. hybridus suggest that it is possible that this plant may contain molecules with similar effect to Nmethyl-carbamates. Snails poisoned by carbamates become immobilized as the muscle tonus is lost $[19,22]$ claimed that this compound interferes with the neural control of feeding. Carbamate molluscicides are known to act as nerve toxins by inhibition of cholinesterase [23,24]. Cytotoxic effects induced by carbamates have been recorded [22,25,26].

In conclusion, the findings of this study indicate that Psidium guajava is not effective against Biomphalaria pfeifferi. Exposure of $B$. pfeifferi to the various concentrations of Psidium guajava extract did not cause meaningful toxicity to the snails compared to the untreated water. From the observations, it is concluded that Aloe secundiflora, Aspilia pluriseta, Balanites aegyptiaca, Azadirachta indica and Amaranthus hybridus were found to have molluscicidal effect against B. pfeifferi. Crude extracts of these plants caused death of the snails at the varying concentrations. The best results in terms of toxicity to the vector snail were exhibited by Amaranthus hybridus followed by Azadirachta indica. Extracts of these two plants could be more preferred for development of a molluscicide as they resulted in high number of dead snails. Crude organic extracts should present $\mathrm{LC}_{90}$ below $20 \mathrm{ppm}$ to be considered a good molluscicide candidate for direct application in infested water [2]. However, it is possible that extracts active between 20 and $100 \mathrm{ppm}$ could contain small amounts of very active components, which could be isolated and/or concentrated using simple procedures, or even obtained from other plants known to produce it in larger amounts. Therefore, the above active extracts deserve further studies in order to identify and characterize their molluscicidal components.

\section{References}

1. Chitsulo L, Engels D, Montresor A, Savioli L (2000) The global status of schistosomiasis and its control. Acta Trop 77: 41-51.

2. (1985) The control of schistosomiasis. Report of a WHO Expert Committee. World Health Organ Tech Rep Ser 728: 1-113.

3. Jolcelyn D (2004) Schistosomiasis. Medical Ecology 39-43

4. WHO Expert Committee (2002) Prevention and control of schistosomiasis and soil-transmitted helminthiasis. World Health Organ Tech Rep Ser 912: 1-57.

5. Liang YS, Coles GC, Doenhoff MJ, Southgate VR (2001) In vitro responses of praziquantel-resistant and -susceptible Schistosoma mansoni to praziquantel. Int J Parasitol 31: 1227-1235

6. Danso-Appiah A, De Vlas SJ (2002) Interpreting low praziquantel cure rates of Schistosoma mansoni infections in Senegal. Trends Parasitol 18: 125-129.

7. Hostettmann K, Lea PJ (1987) Biologically Active Natural Products. Oxford Science Publication, Oxford.

8. Agarwal RA, Singh DK (1988) Harmful gastropods and their control. Acta Hydrochimica et Hydrobiologi 16: 113-138.

9. Alard F, Geerts S, Triest L (1991) Toxicity of the molluscicidal plant, Ambrosia maritima $L$., to aquatic non-target organisms. Toxicon 29: 745-750.

10. Ndamba J, Nyazema N, Makaza N, Anderson C, Kaondera KC (1994) Traditional herbal remedies used for the treatment of urinary schistosomiasis in Zimbabwe. J Ethnopharmacol 42: 125-132.

11. Sparg SG, van Staden J, Jäger AK (2000) Efficiency of traditionally used South African plants against schistosomiasis. J Ethnopharmacol 73: 209-214.

12. 12. Mølgaard $P$, Nielsen $S B$, Rasmussen DE, Drummond RB, Makaza N, et al. (2001) Anthelmintic screening of Zimbabwean plants traditionally used against schistosomiasis. J Ethnopharmacol 74: 257-264

13. Kofi-Tsekpo WM, Rukunga GM, Aluoch JA, Khan B, Waiyaki PG (1985) A preliminary investigation of a traditional medicine (KRM 913) as a potential antimalarial and antiparasitic agent. Proceedings of the loth Annual Medical Scientific Conference, Nairobi Kenya 1989 25-28.

14. Ndamba J, Chandiwana SK (987) A report on the geographical variation in the molluscicidal potency of Phytolacca dodecandra berries in Zimbabwe. A report on the Second International Workshop, UNICEF, New York. 
Citation: Mwonga KB, Waniki NENM, Dorcas YS, Piero NM (2015) Molluscicidal Effects of Aqueous Extracts of Selected Medicinal Plants from Makueni County, Kenya. Pharm Anal Acta 6: 445. doi:10.4172/21532435.1000445

15. Sudarov Z, Krstic Z (1965) Snail Control In The Prevention Of Bilharziasis. Monogr Ser World Health Organ 50: 7-255.

16. Duncan J, Sturrock RF (1987) Laboratory evaluation of potential plant molluscicides. Plant molluscicides. Chichester and New York: John Wiley and Sons Limited, pp: 251-265

17. Hoste H, Torres-Acosta JF, Alonso-Diaz MA, Brunet S, Sandoval-Castro C (2008) Identification and validation of bioactive plants for the control of gastrointestinal nematodes in small ruminants. Trop Biomed 25: 56-72.

18. Thomas JD, Asseffa D (1979) Behavioral responses to amino acids by juvenile Biomphalaria glabrata, a snail host of Schistosoma mansoni. Comparative Biochemical Physiology, 63: 99-108

19. Godan D (1983) Pest slugs and snails. Springel esporr-Verlag, Berlin Heidelberg, New York 445.

20. Triebskorn R, Ebert D (1989) The importance of mucus production in slugs' reaction to molluscicides and the impact of molluscicides on the mucus producing system 373-378.
21. Port CN, Port GR (1986). The biology and behavior of slugs in relation to crop damage and control. Agricultural Zoology Reviews 255-299.

22. Triebskorn R, Christensen K, Heim I (1998) Effect of orally and dermally applied metaldehyde on mucus cells of slugs (Deroceras reticulatum) depending on temperature and duration of exposure. Journal of Molluscan Studies 64: 467 487

23. Wilkinson CF (1976) Insecticide Biochemistry and physiology, Heyden Verlag, London.

24. Young AG, Wilkins RM (1989) A new technique for assessing the contact toxicity of molluscicides to slugs. Journal of Molluscan Studies 53: 533-536.

25. Triebskorn R, Kunast C (1990) Ultrastructural changes in the digestive system of Deroceras reticulatum (Mollusca, Gastropoda) induced by lethal and sub lethal concentrations of the carbamate molluscicide cloethocarb. Malacologia 32: 87-104.

26. Triebskorn R, Hendeson IF, Martin AP, Kohler HR (1996) Slugs as target and non-target organisms for environmental chemicals. Symposium proceeding No.66, British crop protection council, Farnham 65-72. 